\title{
INCIDÊNCIA DE Rhizoctonia sp. EM PLANTAS DE ALFACE (Lactuca sativa L) CULTIVADAS EM SOLO COM POLÍMERO HIDRORETENTOR
}

\author{
Incidence of Rhizoctonia sp. in Plants of Lettuce (Lactuca sativa l.) \\ Cultivated in Soil With Hydrophilic Polymer
}

Bianca. Nadal Foltran ${ }^{1}$

Eduardo Silva Teixeira ${ }^{2}$

\section{Resumo}

O objetivo deste trabalho foi avaliar a eficiência da aplicação de polímero hidroretentor no solo quanto às condições mais favoráveis para a incidência de Rhizoctonia sp. em plantas de alface, bem como de testar a eficiência do respectivo produto na irrigação e desenvolvimento desta cultura. O experimento foi realizado em Casa de Vegetação sem controle ambiental, do Departamento de Solos e Engenharia Agrícola, Setor de Ciências Agrárias da Universidade Federal do Paraná. As plantas foram acondicionadas em vasos plásticos com aproximadamente $900 \mathrm{~g}$ de solo esterilizado. O polímero foi incorporado ao solo seco utilizando-se quantidades de zero, 2, 4 e $8 \mathrm{~g} / \mathrm{kg}$ de solo. A inoculação do fungo se deu pela transferência e incorporação de três discos de micélio. $O$ uso de polímero hidroretentorno solo não demonstrou condições mais favoráveis para a incidência de Rhizoctonia sp. O tratamento com maior quantidade de polímero apresentou o maior teor de umidade do solo e os maiores valores para peso de folhas, peso de raízes e peso total, diferindo estatisticamente de todos os demais. $\mathrm{O}$ tratamento com $2 \mathrm{~g} / \mathrm{kg}$ de polímero não mostrou diferença estatística dos tratamentos que não continham o produto para peso de folhas, peso de raízes e peso total.

Palavras-chave: Polímero; Alface; Rhizoctonia sp.

\section{Abstract}

The objective of this work was to evaluate the efficiency of the hydrophilic polymer application in the soil with relationship to the most favorable conditions for the incidence of Rhizoctonia sp. in lettuce plants, as well as of testing the efficiency of the respective product in the irrigation and development of this culture. The experiment was made in greenhouse without environmental control, of the Soils and Agricultural Engineering Department, Agrarian Sciences Center of the Federal University of Parana. The plants were conditioned in plastic vases with approximately $900 \mathrm{~g}$ of sterilized soil. The polymeramounts were incorporate to the dry soil being used with zero, 2, 4 and $8 \mathrm{~g} / \mathrm{Kg}$ of soil. The inoculation of the mushroom was made through the transfer and incorporation of three mycelium disks. The use of hydrophilic polymer in the soil did not demonstrate more favorable conditions for the incidence of Rhizoctonia sp. The treatment with larger amount of polymer presented the largest humidity amount in the soil and the largest values of leaves, roots and total weight, differing statistically from all others. The treatment with $2 \mathrm{~g}$ of polymer per $\mathrm{kg}$ of soil did not presented statistical difference from the treatments that did not contain the product in leaves, roots and total weight.

Keywords: Polymer; Lettuce; Rhizoctonia sp.

1 Eng. Agrônoma - Curso de Pós-Graduação em Ciência do Solo - Universidade Federal do Paraná - Setor de Ciências Agrárias R. dos Funcionários, 1450 - Curitiba - PR. e-mail: bia nf@uol.com.br

2 Prof. Dr. - Universidade Federal do Paraná - Setorde Ciềncias Agrárias Depto. de Solos e Engenharia Agrícola - R. dos Funcionários, 1450 CEP 80035-050 - Curitiba - PR. e-mail: eduardo@ufpr.br 


\section{Introdução}

A quantidade de água disponível para as plantas é um dos principais fatores que regulam a qualidade e eficiência de seu crescimento, bem como suas respostas produtivas. Dentre as olerícolas, a alface destaca-se por ser uma hortaliça altamente exigente em água, necessitando, assim, de sua freqüente aplicação (LÉDO et al., 2000). Quando convenientemente irrigada, têm-se plantas bem desenvolvidas e de melhor qualidade, caso contrário, o crescimento é prejudicado, resultando em plantas com folhas menores e rígidas, cabeças pequenas e mal formadas (MURAYAMA, 1973). Diversos autores constataram a estreita relação entre o nível de umidade do solo e o crescimento e rendimento da cultura, enfatizando a importância da manutenção de um teor de umidade do solo, alto e uniforme, por todo o ciclo vegetativo (HAMADA; TESTEZLAF, 1995).

O uso de polímero hidroretentor no solo permite a esse manter um teor de umidade uniforme, disponibilizando-a às plantas, com redução de perdas de água e manutenção, uma umidade ideal. O polímero hidroretentor é um condicionador de solo (qualquer substância que adicionada ao solo melhora suas propriedades físicas) e serve como reservatório de água no solo, aumentando sua disponibilidade às plantas (SAMPAT, 1973 citado por BALENA, 1998). Quando seco, este produto possui forma granular e quebradiça, e quando em contato com água, cada grânulo incha como uma partícula gelatinosa, elástica e macia, absorvendo e armazenando em água muitas vezes o seu próprio peso (BALENA, 1998). As partículas gelatinosas, com seus movimentos de expansão e contração devido à absorção da água e a devolução desta água para as plantas, formam espaços no solo que permitem a penetração do ar e o aprofundamento das raízes. $\mathrm{O}$ efeito duradouro do polímero é assegurado devido à alta estabilidade mecânica e biológica dos polímeros hidroabsorventes que o compõem. Incorporados ao solo, eles têm produzido resultados variáveis nas características de retenção de água e redução das imigações (BALENA, 1998).

Essa umidade mantida no solo por maior período de tempo pelo uso do polímero auxilia na otimização do crescimento das plantas (MORAES, 2001). No entanto, a umidade constitui fator determinante para a ocorrência de doenças em plantas (CANTERI et al., 1999; KRUGNER, 1978).
A água do solo é a forma de umidade mais atuante na predisposição de plantas ao ataque de agentes patogênicos, uma vez que regula a atividade ou incidência dos patógenos na área onde se estabeleceram (BERGAMIM FILHO, 1995; PONTE, 1988). No que concerne aos fungos fitopatogênicos, a maioria requer elevada umidade para 0 seu crescimento (PONTE, 1988).

São encontrados numerosos exemplos na literatura sobre os efeitos de falta de água ou de excesso de umidade do solo, causando estresse nas plantas e tornando-as mais susceptíveis a certos patógenos (KRUGNER, 1978). O excesso de água e a inundação do solo diminuem a disponibilidade de oxigênio para as raízes, comprometendo seu desenvolvimento e, conseqüentemente, a absorção de água e nutrientes. Como resultado, a planta pode tornar-se mais susceptível ao ataque de patógenos. A presença de um alto teor de água no solo também pode contribuir para aumentar a suculência dos tecidos, facilitando a penetração e a colonização por patógenos de natureza diversa (BERGAMIM FILHO, 1995). Existem vários fungos de solo que encontram nele condições favoráveis para desenvolvimento e posterior infecção do hospedeiro. A Rhizoctonia sp. é um exemplo desses fungos (FENILLE; SOUZA, 1999; BERGAMIM FILHO, 1995; CARVALHO; TOKESHI, 1980; MESSIAEN; LAFON, 1976). Este patógeno vive saprofiticamente na matéria orgânica do solo ou em restos de cultura, ataca grande número de espécies vegetais causando, comumente, tombamento e podridão de raiz e de colo e é um patógeno agressivo, que atua destruindo o hospedeiro e obtendo nutrientes à custa de sua decomposição (FENILIE; SOUZA,1999; BERGAMIM FILHO, 1995; TOKESHI; BERGAMIN FILHO, 1980). Em alface, a Rhizoctonia sp. pode causar, em mudas e plantas mais novas, tombamento e podridão de colo e raiz e em plantas adultas a queima-da-saia, doença muito importante na cultura, que pode causar prejuízos acentuados no cultivo e vir a destruir quase ou todas as plantas (BERGAMIM FILHO, 1995).

O objetivo deste trabalho foi avaliar a eficiência da aplicação de polímero hidroretentor no solo quanto às condições mais favoráveis para a incidência de Rhizoctonia sp. em plantas de alface, bem como de testar a eficiência do respectivo produto na irrigação e desenvolvimento desta cultura. 


\section{Material e métodos}

O experimento foi realizado em Casa de Vegetação sem controle ambiental, do Departamento de Solos e Engenharia Agrícola, Setor de Ciências Agrárias da Universidade Federal do Paraná no município de Curitiba, latitude de $25^{\circ} \mathrm{S}$, longitude de $49^{\circ} 16^{\prime} \mathrm{W}$ e altitude aproximada de $930 \mathrm{~m}$. O clima da região, segundo a classificação de Koeppen (Cfb), corresponde a um clima subtropical super úmido, com verão fresco e geadas demasiadamente freqüentes (média de 5 geadas/ano). A temperatura média anual é de $16,5^{\circ} \mathrm{C}$, com média do mês mais quente e mais frio de 20,1 e $12,0^{\circ} \mathrm{C}$, respectivamente. $\mathrm{O}$ mês mais chuvoso é janeiro e o menos é agosto.

O delineamento experimental foi inteiramente casualizado, sendo a análise estatística realizada pelo teste de Tuckey ao nível de 5\% de probabilidade.

As plantas foram acondicionadas em vasos plásticos esterilizados com hipoclorito de sódio, cada um com aproximadamente $900 \mathrm{~g}$ de solo. Utilizou-se um solo arenoso, previamente esterilizado em forno e deixado em descanso por 15 dias. O polímero foi incorporado ao solo seco utilizando-se três quantidades diferentes do produto: $2 ; 4$ e $8 \mathrm{~g} / \mathrm{kg}$ de solo, respectivamente. As mudas foram transplantadas para os vasos com 7 dias de idade.

O isolado de Rhizoctonia sp. foi obtido por culturas já existentes e cultivado em BDA. A inoculação do fungo se deu por transferência e incorporação de três discos de micélio das culturas crescidas para o solo de cada um dos vasos irrigados na capacidade de campo. Estes discos foram colocados bem próximos às raízes das plantas.

Os tratamentos constituíram-se de: vaso com quantidade zero de polímero sem inoculação (T1); vaso com quantidade zero de polímero inoculado com Rhizoctonia sp. (T2); vaso com quantidade $2 \mathrm{~g} / \mathrm{kg}$ de solo de polímero inoculado com Rhizoctonia sp. (T3); vaso com quantidade $4 \mathrm{~g} / \mathrm{kg}$ de solo de polímero inoculado com Rhizoctonia sp. (T4) e vaso com quantidade $8 \mathrm{~g} / \mathrm{kg}$ de solo de polímero inoculado com Rhizoctonia sp. (T5). Cada tratamento continha seis vasos, totalizando trinta repetições.

Após incorporação do polímero e transplante das mudas, realizou-se a primeira irrigação até o momento do solo atingir sua capacidade de campo. Primeiramente, pesou-se o vaso com solo seco (valor 1). Em seguida, foi adicionada água até esta começar a escorrer pelo fundo do vaso, indicando, assim, que a capacidade de campo foi atingida. Realizou-se nova pesagem (valor 2 ). Subtraindo o peso do vaso com solo irrigado do peso do vaso com solo seco, obteve-se o valor correspondente ao total de água requerida pelo solo para atingir sua capacidade de campo (valor 3). A quantidade de água a ser adicionada nas próximas irrigações foi determinada de acordo com o valor 3 obtido. Estipulou-se um total de água equivalente a $70 \%$ da capacidade de campo referente a cada repetição (valor 4).

Foi esperado os vasos apresentarem valores menores que o valor 4 estipulado para iniciarem-se as irrigações. Para cada irrigação realizada, pesava-se o vaso e comparava este valor obtido com o valor estabelecido de água requerida (valor 4), adicionando-se água até atingir tal valor. A diferença entre o peso do vaso antes e após a irrigação forneceu a quantidade de água utilizada. Foram realizadas três irrigações por semana, com intervalos de um, um e dois dias respectivamente, totalizando, durante a condução do experimento, dezessete irrigações.

A avaliação da doença foi feita pela análise visual, uma vez por semana. Para cada avaliação efetuada, anotou-se o total de plantas que apresentaram sintomas de infecção por Rhizoctonia sp. Essas avaliações foram realizadas até as plantas terem completado 50 dias de idade.

Ao final do experimento, avaliou-se o teor de umidade do solo e o desenvolvimento das plantas em cada tratamento. Para determinar o teor de umidade, pesou-se certa quantidade de solo úmido, sendo esta mesma levada para secagem em estufa a $105^{\circ} \mathrm{C}$ durante 24 horas. Utilizou-se então a seguinte equação: (peso do solo úmido - peso do solo seco $/$ peso do solo úmido $)$ x $100 \%$

O desenvolvimento das plantas foi avaliado pelos parâmetros peso verde de folhas, peso verde de raízes (medidos em balança de precisão de 2 casas decimais) e número de folhas.

\section{Resultados e discussão}
A) Incidência de Rhizoctonia sp.
Não houve sintomas de infecção pelo fun- go nas plantas em todos os tratamentos. 
Dentre os fatores que contribuíram para tal resultado, a umidade do solo, mantida sempre no teor de $70 \%$ da capacidade de campo, pode não ter sido favorável ao desenvolvimento do fungo. Segundo Bateman (1961), citado por Fenille e Souza (1999), observações realizadas em várias culturas demonstraram que o aumento na umidade do solo de $30 \%$ para $70-80 \%$ da capacidade de campo pouco aumentou a infecção, sendo que em altos níveis de umidade a infecção foi reduzida. Fenille e Souza (1999), estudando o efeito da umidade do solo na patogenicidade de Rhizoctonia solani em feijoeiro, constataram que a incidência deste fungo foi independente das condições de umidade. De acordo com Ponte (1988), a condição de alta umidade no solo para desenvolvimento da Rhizoctonia prevalece como referência e não como regra fixa, posto que a interferência de outros fatores pode modificar o comportamento individual em relação à umidade.

A temperatura pode ter sido um fator de interferência no comportamento do fungo. Bergamin Filho (1995) cita que a Rhizoctonia exige temperaturas mais amenas para seu desenvolvimento, entre $15^{\circ}$ a $25^{\circ}$. No local onde este experimento foi conduzido, várias vezes foram verificadas temperaturas acima do respectivo intervalo.

Outro fator considerado refere-se à quantidade de inóculo colocado ser insuficiente. Chung (1988), citado por Fenille e Souza (1999), afirmou que existe uma correlação positiva entre a densidade de inóculo no solo e a severidade de doença causada por Rhizoctonia.

A ausência de matéria orgânica no solo talvez tenha contribuído para que a infecção não se manifestasse, uma vez que Fenille e Souza (1999) constataram que o aumento do potencial supressivo deste fungo está provavelmente relacionado com a disponibilidade de nutrientes, principalmente nitrogênio e carbono fornecidos pelos materiais orgânicos presentes no solo.

B) Eficiência do polímero na irrigação da cultura

A eficiência do polímero foi avaliada de acordo com a quantidade de água utilizada nas irrigações realizadas. Os tratamentos com adição de polímero necessitaram de maior quantidade de água para chegarem à capacidade de campo em relação àqueles que não continham o produto (TABELA 1).

\section{TABELA 1 - Quantidade de água (m) para atingir capacidade de campo.}

Table 1 - Amount of water (ml) to reach field capacity

\begin{tabular}{c|c}
\hline Tratamentos & Quantidade de água $(\mathrm{ml})$ \\
\hline T1 & 273,63 \\
T2 & 232,04 \\
T3 & 348,86 \\
T4 & 414,69 \\
T5 & 533,74 \\
\hline
\end{tabular}

A quantidade de água para atingir a capacidade de campo aumentou de acordo com a dose do produto. $\mathrm{O}$ tratamento contendo a maior dose de polímero (T5) foi o que mais requeriu água, seguido por T4 e T3. O tratamento sem incorporação do produto apresentou valor bem menor em relação aos demais. Esta maior quanti- dade requerida pelo solo contendo polímero devese à capacidade desse de reter a água adicionada. Os tratamentos T1 e T2 necessitaram de quantidades de água próximas entre si para manter o solo com $70 \%$ de sua capacidade de campo. Na Tabela 2 apresenta-se a quantidade média de água utilizada nas irrigações posteriores à primeira. 
TABELA 2 - Quantidade média de água utilizada $(\mathrm{ml})$ nas irrigações subseqüentes à primeira quando a capacidade de campo do solo foi determinada.

Table 2 - Average amount of water used (ml) in the subsequent irrigations to the first when the field capacity of the soil was determined

\begin{tabular}{c|c}
\hline Tratamentos & Quantidade de água $(\mathrm{ml})$ \\
\hline T1 & 39,80 \\
T2 & 39,71 \\
T3 & 42,15 \\
T4 & 46,26 \\
T5 & 57,76 \\
\hline
\end{tabular}

Durante a condução deste estudo, os tratamentos 4 e 5 necessitaram de uma quantidade média de água por irrigação relativamente maior que os registrados pelos tratamentos 1,2 e 3, cujas quantidades médias ficaram próximas entre os três tratamentos.

Estes valores fornecem a sugestão de estender o intervalo de irrigação para os tratamen- tos com presença de polímero, principalmente para o de maior dose, uma vez que a quantidade média de água utilizada neste último tratamento é bem superior à quantidade média de água utilizada nos tratamentos sem a adição do produto.

A Tabela 3 fornece o total de água utilizada na realização deste experimento.

TABELA 3 - Quantidade total de água (ml) utilizada durante a condução do experimento. Table 3 - Total amount of water (ml) used during the conduction of the experiment.

\begin{tabular}{c|c}
\hline Tratamentos & Quantidade de água $(\mathrm{ml})$ \\
\hline T1 & 950,31 \\
T2 & 907,04 \\
T3 & $1.065,34$ \\
T4 & $1.201,09$ \\
T5 & $1.515,66$ \\
\hline
\end{tabular}

O valor obtido em T5 indica um total de água utilizada na irrigação das plantas de alface muito maior que os encontrados para os tratamentos sem polímero. As quantidades de água utilizadas para manter, em cada tratamento, o solo em
$70 \%$ da sua capacidade de campo (irrigações realizadas após 21/8) mostrou aparente diferença entre si, acentuada em T5.

Na Tabela 4 pode-se verificar tais dados. 


\section{TABELA 4 - Quantidade total de água utilizada $(\mathrm{ml})$ nas irrigações subsequentes à primeira onde foi determinada a capacidade de campo.}

Table 4 - Total amount of water used (ml) in the subsequent irrigations to the first when the field capacity was determined.

\begin{tabular}{c|c}
\hline Tratamentos & Quantidade de água $(\mathrm{ml})$ \\
\hline T1 & 676,68 \\
T2 & 675,00 \\
T3 & 716,48 \\
T4 & 786,40 \\
T5 & 981,92 \\
\hline
\end{tabular}

Os tratamentos sem polímero (T1 e T2) e o que continha menor dose do produto (T3) apresentaram valores próximos de quantidade de água utilizada. T4 mostrou valor um pouco acima de T3. O tratamento com dose de $8 \mathrm{~g} / \mathrm{kg}$ de solo de polímero apresentou quantidade relativamente maior que as outras obtidas.

Os gráficos apresentados acima permitem constatar que a incorporação de polímero hidroretentor no solo altera a sua condição natural quanto à necessidade de água para a capacidade de campo ser atingida. Quanto mais polímero presente no solo, maior a capacidade de campo deste.

Um dos fatores que podem ter contribuído para que os tratamentos com adição de polímero utilizassem maior quantidade de água nas irrigações realizadas em relação aos tratamentos sem a presença do produto, e não o contrário, seja o fato dos valores estabelecidos para as irrigações terem sido estipulados com base na capacidade de campo individual de cada tratamento (solo + doses de polímero), e não considerando a condição natural de capacidade de campo do solo.

Quanto ao teor de umidade do solo (TABELA 5), o tratamento com maior quantidade de polímero apresentou o maior teor de umidade. Os tratamentos T3 e T4 mostraram valores muito próximos entre si, bem como os tratamentos sem incorporação do produto.

\section{TABELA 5 - Teor de umidade médio (\%) do solo}

Table 5 - Average contents of humidity (\%) of the soil

\begin{tabular}{c|c}
\hline Tratamentos & Teor de umidade (\%) \\
\hline T1 & 8,99 \\
T2 & 9,42 \\
T3 & 10,69 \\
T4 & 10,73 \\
T5 & 11,63 \\
\hline
\end{tabular}


C) Eficiência do polímero no desenvolvimento da cultura

Verificou-se que o desenvolvimento das plantas de alface foi maior nos tratamentos que continham polímero, especialmente nas doses de 4 e $8 \mathrm{~g} / \mathrm{kg}$ de solo do produto. 0 crescimento, principalmente foliar, foi muito maior em relação às plantas cultivadas nos vasos sem presença de polímero. Na Tabela 6 apresentam-se os valores de peso médio de folhas. Nota-se que o tratamento que continha maior quantidade de polímero apresentou valor bem maior que os demais, diferindo estatisticamente entre eles. T4 e T3 apresentaram valores intermediários, não diferindo entre si, no entanto T3 não apresentou diferença significativa se comparado com os tratamentos que não continham polímero, os quais apresentaram os menores valores para peso verde de folhas.

\section{TABELA 6 - Peso verde médio (g) de folhas.}

Table 6 - Average green weight (g) of leaves.

\begin{tabular}{c|c}
\hline Tratamentos & Peso $(g)$ \\
\hline T5 & $17,55 \mathrm{a}^{*}$ \\
T4 & $11,10 \mathrm{~b}$ \\
T3 & $9,75 \mathrm{bc}$ \\
T2 & $6,92 \mathrm{c}$ \\
T1 & $6,20 \mathrm{c}$ \\
\hline
\end{tabular}

*Médias seguidasdemesma letra não diferem entresi pelo testedeTukey ao nível de $5 \%$ de probabilidade.

Quanto ao peso verde de raízes (TABELA 7), o tratamento T5 apresentou diferença estatística significativa em relação aos demais tratamentos, não diferindo, porém, de T4. Os tratamentos sem incorporação de polímero e o que tinham o produto em menor quantidade não diferiram estatisticamente entre si.

\section{TABELA 7 - Peso verde médio (g) de raízes.}

Table 7 - Average green weight (g) of roots.

\begin{tabular}{c|c}
\hline Tratamentos & Peso $(g)$ \\
\hline T5 & $2,97 \mathrm{a}^{*}$ \\
T4 & $1,85 \mathrm{ab}$ \\
T1 & $1,19 \mathrm{~b}$ \\
T3 & $1,15 \mathrm{~b}$ \\
T2 & $1,03 \mathrm{~b}$ \\
\hline
\end{tabular}

* Médias seguidas de mesma letra não diferem entre si pelo teste de Tukey ao nível de $5 \%$ de probabilidade.

Para peso total (TABELA 8), T5 apresentou o maior valor, vindo a diferir de todos os de- mais tratamentos. Observa-se que não houve diferença estatística entre os tratamentos T1, T2 e T3. 


\section{TABELA 8 - Peso verde total médio (g) das plantas.}

Table 8 - Total average green weight (g) of the plants.

\begin{tabular}{c|c}
\hline Tratamentos & Peso $(\mathrm{g})$ \\
\hline T5 & $20,51 \mathrm{a}^{*}$ \\
T4 & $12,95 \mathrm{~b}$ \\
T3 & $10,91 \mathrm{bc}$ \\
T2 & $7,95 \mathrm{c}$ \\
T1 & $7,39 \mathrm{c}$ \\
\hline
\end{tabular}

* Médias seguidas de mesma letra não diferem entre si pelo teste de Tukey ao nível de 5\% de probabilidade.

Com relação ao número de folhas (TABELA 9), o tratamento incorporado com maior quantidade de polímero mostrou o maior valor,
18 folhas. Os tratamentos que não continham 0 produto apresentaram 12 e 13 folhas, respectivamente.

\section{TABELA 9 - Número médio de folhas.}

Table 9 - Average leaf number.

\begin{tabular}{c|c}
\hline Tratamentos & Número de folhas \\
\hline T1 & 12 \\
T2 & 13 \\
T3 & 15 \\
T4 & 14 \\
T5 & 18 \\
\hline
\end{tabular}

\section{Conclusões}

- O uso de polímero hidroretentor no solo não demonstrou condições mais favoráveis para a incidência de Rhizoctonia sp. em plantas de alface.

- O uso de polímero hidroretentor no solo altera a sua condição natural quanto à necessidade de água para a capacidade de campo ser atingida.

- A quantidade de água requerida pelo solo e planta aumentou de acordo com o aumento da dose do produto utilizado.
- O tratamento com maior quantidade de polímero apresentou o maior teor de umidade do solo. Os tratamentos com $4 \mathrm{~g} / \mathrm{kg}$ e $2 \mathrm{~g} / \mathrm{kg}$ de polímero mostraram valores muito próximos entre si, bem como os tratamentos sem incorporação do produto.

- O tratamento com maior quantidade de polímero apresentou os maiores valores de peso de folhas, peso de raízes e peso total, diferindo estatisticamente de todos os demais.

- O tratamento com $2 \mathrm{~g} / \mathrm{kg}$ de polímero não mostrou diferença estatística dos tratamentos que não continham o produto para peso de folhas, peso de raízes e peso total. 


\section{Referências}

BALENA, S. P. Efeito de polímeros hidroretentores naspropriedadesfísicas ehidráulicas de doismeios porosos. 1998. 57f. Dissertação (Mestrado em Agronomia, Ciência do Solo) - Setor de Ciências Agrárias, Universidade Federal do Paraná, Curitiba, 1998.

BERGAMIM FILHO, A.; KIMATI, H.; AMORIM, L; Manual de Fitopatologia: princípios e conceitos. 3 ed. São Paulo, SP: Agronômica Ceres, 1995. p. 919 .

CANTERI, M. G.; DALIA PRIA, M.; SILVA, O. C. Principais doenças fúngicas do feijoeiro: orientação para manejo econômico e ecológico. Ponta Grossa: Editora da UEPG, 1999. p. 178.

CARVALHO, P. C. T.; TOKESHI, H. Doenças da alface: Lactuca sativa. In: GALU, F. (Coord.) Manual de Fitopatologia: doenças das plantas cultivadas. São Paulo, SP: Agronômica Ceres, 1980. p. 23-28.

FENILLE, R. C.; SOUZA, N. L. Efeitos de materiais orgânicos e da umidade do solo na patogenicidade de Rhizoctonia solani Kuhn GA-4 HGI ao feijoeiro. Pesquisa Agropecuária Brasileira, Brasília, v. 34, n. 10, p. 1959-1967, 1999.

HAMADA, E.; TESTEZLAF, R. Desenvolvimento e produtividade da alface submetida a diferentes lâminas de água através da irrigação porgotejamento.
Pesquisa Agropecuária Brasileira, Brasília, v. 30, n. 9, p. 1201-1209, 1995.

KRUGNER, T. L Ação do ambiente sobre doenças de plantas. In: GALLI, F. (Coord.) Manual de Fitopatologia: princípios e conceitos. São Paulo, SP: Agronômica Ceres, 1978. p. 102-120.

LÉDO, F. J. S.; SOUZA, J. A.; SILVA, M. R. Desempenho de cultivares de alface no Estado do Acre. Horticultura Brasileira, Brasília, v. 18, n. 3, p. 225-228, 2000.

MESSIAEN, C. M.; LAFON, R. Enfermedades de las hortalizas. Barcelona: Oikos-tau, 1976. p. 361.

MORAES, O. Efeito do uso de polímero hidroretentor no solo sobre o intervalo de irrigação na cultura da alface (Lactuca sativa, L.) 2001. 73 f. Tese (Doutorado em Agronomia, Irrigação e Drenagem) - Escola Superior de Agricultura Luiz de Queiroz, Universidade de São Paulo, São Paulo, 2001.

MURAYAMA, S. Horticultura. 2. ed. Campinas: Instituto campineiro de Ensino Agrícola, 1973. p. 317.

PONTE, J. Fitopatologia: princípios e aplicações. 2. ed. São Paulo, SP: Nobel, 1988. p. 250.

TOKESHI, H.; BERGAMIN FILHO, A. Doenças da batata. In: GALLI, F. (Coord.) Manual de Fitopatologia: doenças das plantas cultivadas. São Paulo, SP: Agronômica Ceres, 1980. p. 102-120. 